\title{
Christian Rückert
}

\section{Effektive Selbstverteidigung und Notwehrrecht}

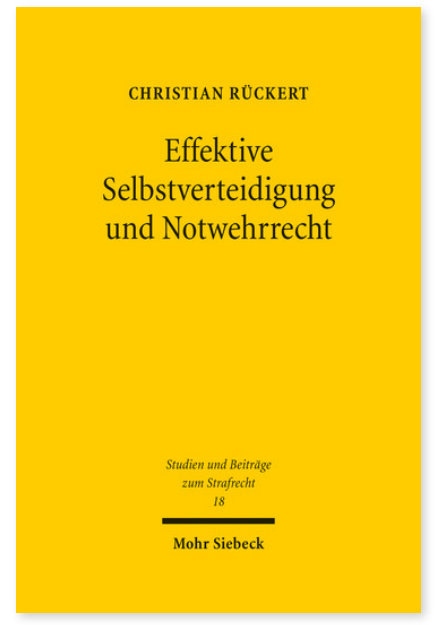

2017. XXII, 606 Seiten. StudStR 18

ISBN 978-3-16-155292-2

DOI 10.1628/978-3-16-155292-2

eBook PDF 144,00€

ISBN 978-3-16-155291-5

Leinen $144,00 €$
Das »scharfe Schwert« des Notwehrrechts verleiht dem Angegriffenen im Ernstfall die Befugnis, den Angreifer zu töten. Entscheidend für den Ausgang eines Notwehrprozesses sind dabei häufig der Zeitpunkt und die Intensität der Verteidigungsmaßnahme. Durfte der Angegriffene bereits zustechen, bevor der Aggressor seinerseits sein Messer zieht? Durfte er sofort auf den Angreifer schießen oder hätte er einen Warnschuss abgeben müssen? Diesen Fragen wendet sich Christian Rückert zu und stellt den Auslegungskriterien der Rechtsprechung und der Strafrechtswissenschaft Erkenntnisse aus dem Bereich der Rechtsmedizin und der Sozialpsychologie, sowie das Erfahrungswissen anerkannter Selbstverteidigungsexperten gegenüber. Er zieht daraus Schlüsse für die praktische Anwendung des Notwehrrechts durch Tatund Revisionsgerichte.

Christian Rückert Geboren 1986; Studium der Rechtswissenschaft an der Universität Erlangen-Nürnberg; 2011 Erstes Juristisches Staatsexamen; Rechtsreferendariat am Oberlandesgericht Nürnberg; 2013 Zweites Juristisches Staatsexamen; wissenschaftlicher Mitarbeiter an der Universität Erlangen-Nürnberg und der Universität Marburg; 2017 Promotion; seit 2017 Akademischer Rat auf Zeit am Lehrstuhl für Strafrecht, Strafprozessrecht, Internationales Strafrecht und Völkerrecht der Universität Erlangen-Nürnberg und Wissenschaftlicher Mitarbeiter in Nebentätigkeit am Institut für Informations- und Wirtschaftsrecht im Zentrum für Angewandte Rechtswissenschaft des Karlsruher Instituts für Technologie (KIT).

\section{Jetzt bestellen:}

https://mohrsiebeck.com/buch/effektive-selbstverteidigung-und-notwehrrecht-9783161552922?no_cache=1 order@mohrsiebeck.com

Telefon: +49 (0)7071-923-17

Telefax: +49 (0)7071-51104 